\title{
A RECEPÇÃO DE PIERRE BOURDIEU NA SOCIOLOGIA DA EDUCAÇÃO BRASILEIRA
}

D) Amurabi Oliveira ${ }^{\mathrm{I}}$

(D) Camila Ferreira da Silva II

I Universidade Federal de Santa Catarina (UFSC), Florianópolis (SC), Brasil; amurabi_cs@hotmail.com

II Universidade Federal do Amazonas (Ufam), Manaus (AM), Brasil; ferreira.camilasilva@gmail.com

\section{Resumo}

O alcance e a envergadura dos trabalhos de Pierre Bourdieu são atestados ao redor do mundo desde suas primeiras publicações na década de 1960, passando pelas traduções que suas obras receberam ao longo do tempo e também pela ampla apropriação que seus constructos teóricos, conceituais e metodológicos têm demonstrado em diferentes áreas do conhecimento por mais de cinco décadas. O presente artigo elege a sociologia da educação brasileira como espaço acadêmico privilegiado para analisar a recepção da obra de Bourdieu no Brasil, ocupando-se das condições de possibilidade da introdução e difusão de seu pensamento e das leituras da obra desse sociólogo que passaram a ser realizadas no país.

PIERRE BOURDIEU • SOCIOLOGIA DA EDUCAÇÃO • BRASIL

\section{PIERRE BOURDIEU'S RECEPTION IN THE SOCIOLOGY OF EDUCATION}

\section{IN BRAZIL}

Abstract
The scope and breadth of Pierre Bourdieu's works have been attested around the world since his first publications in the 1960s, including the translations of his works overtime, as well as the wide appropriation that his theoretical, conceptual, and methodological constructs have demonstrated in different areas of knowledge for over five decades. The present article selects the Brazilian Sociology of Education as a privileged academic space to analyse the reception of Bourdieu's work in Brazil, approaching the conditions for the possibility of introducing and disseminating his ideas and the readings of this sociologist's work in Brazil.

PIERRE BOURDIEU • SOCIOLOGY OF EDUCATION • BRAZIL 


\section{LA RECEPCIÓN DE PIERRE BOURDIEU EN LA SOCIOLOGÍA DE LA EDUCACIÓN BRASILEÑA}

\section{Resumen}

El alcance y la envergadura de los trabajos de Pierre Bourdieu se comprueban alrededor del mundo desde sus primeras publicaciones en la década de 1960, pasando por las traducciones que sus obras recibieron a lo largo del tiempo y también por la amplia apropiación que sus constructos teóricos, conceptuales y metodológicos han demostrado en distintas áreas del conocimiento durante más de cinco décadas. El presente artículo elige la sociología de la educación brasileña como un espacio académico privilegiado para analizar la recepción de la obra de Bourdieu en Brasil, ocupándose de la posibilidad de introducir y difundir su pensamiento y las lecturas de la obra de este sociólogo que se empezaron a realizar en Brasil.

PIERRE BOURDIEU • SOCIOLOGÍA DE LA EDUCACIÓN • BRASIL

\section{LA RECEPTION DE PIERRE BOURDIEU DANS LA SOCIOLOGIE DE L'EDUCATION BRESILIENNE}

\section{Résumé}

L'ampleur et l'envergure des travaux de Pierre Bourdieu sont attestées autour du monde dès ses premières publications dans les années 1960, passant par les traductions de ses œuvres au long du temps et aussi par la vaste appropriation de ses principes téoriques, conceptuels et méthodologiques démontrent dans différents domaines du savoir pour plus d'une cinquantaine d'années. Cet article place la sociologie de l'éducation brésilienne comme l'espace privilegié pour analyser la reception de l'œuvre de Bourdieu au Br ésil, abordant les conditions de possibilités de l'introduction et diffusion de sa pensée, et des lectures de son œuvre qui sont réalisées au Brésil.

PIERRE BOURDIEU • SOCIOLOGIE DE L'ÉDUCATION • BRÉSIL 

alcance em distintas áreas do conhecimento em todo o mundo. No cenário brasileiro, as ciências sociais particularmente têm se debruçado sobre seus escritos desde a década de 1960, e, com diferentes estágios de recepção da obra desse sociólogo (Bortoluci et al., 2015), observa-se uma presença marcante e movimentos crescentes de dispersões temáticas dos usos de sua produção especialmente na antropologia e na sociologia, em detrimento da ciência política (Campos \& Szwako, 2020). O peso de Bourdieu no campo da sociologia da educação (SE) em todo o mundo é amplamente reconhecido, e, ao menos desde os anos de 1960 - com a publicação da obra Os herdeiros (2014/1964) e posteriormente com $A$ reprodução (2008/1970), ambos escritos em parceria com Jean-Claude Passeron -, seu trabalho é considerado um marco nesse campo.

Como bem demonstra Nogueira (1990), ainda que possamos apontar a existência de outras teorias que afirmavam haver uma relação entre escolarização e reprodução das desigualdades sociais, a obra de Bourdieu e Passeron diferencia-se dos demais trabalhos pela articulação entre uma teoria geral do sistema de ensino e os dados empíricos, pela dimensão cultural que destaca nesse processo e ainda por aspectos como originalidade e abrangência de seu enfoque (C. M. M. Nogueira \& M. A. Nogueira, 2002).

Em todo caso, encontra-se ao fundo desse debate um conjunto de pesquisas longitudinais realizadas em distintos países, tais como Robin, em 1963, e Plowden, em 1967, no Reino Unido, e Coleman, em 1966, nos Estados Unidos. Na França, destaca-se a "demografia escolar" desenvolvida no Instituto Nacional de Estudos Demográficos (Inde), bem como o importante papel do Centre de Sociologie Européenne no desenvolvimento das pesquisas em SE (Masson, 2001). Esse conjunto de pesquisas confluía para a mesma direção ao indicar a forte relação entre fracasso escolar e origem social. ${ }^{1}$

A apropriação do trabalho de Bourdieu ocorreu em diversas partes do mundo, incluindo a América Latina, ainda que o substrato empírico de suas análises parta de uma realidade política, social e cultural específica: o sistema de ensino francês. Reconhece-se, todavia, que sua teoria se referia de forma mais ampla aos sistemas de ensino das sociedades modernas capitalistas, e, ainda que possamos problematizar a relação entre centro e periferia no capitalismo, seria plausível indicar que algumas questões lançadas pelo autor poderiam ser pertinentes para se pensar a realidade do Sul Global. ${ }^{2}$

No presente trabalho, busca-se realizar uma breve análise acerca da recepção da obra de Bourdieu na SE brasileira, considerando as particularidades que esse campo assume no Brasil. Diferentemente da abordagem realizada por Catani et al. (2001), que buscaram analisar a incorporação de Bourdieu no campo da educação de uma forma mais geral, com base nos artigos da área, nossa preocupação se circunscreve diretamente ao processo de recepção de Bourdieu na SE. Apesar de dialogarmos com os trabalhos de Bortoluci et al. (2015) e de Peters e Rocha (2020), compreendemos que esses autores, apesar de reconhecerem a relevância de Bourdieu para a SE, tendem a centrar suas análises nesse ponto mais nas resistências encontradas à recepção da obra do sociólogo francês, ao passo em que nós estamos preo-

1 Fugiria de foco e do escopo deste artigo realizar um exame acerca do contexto de produção dessas obras, todavia, para uma análise mais profunda, vide o trabalho de Masson (2001) e Nogueira e Nogueira (2015).

2 As expressões Norte e Sul Global compreendem, em uma perspectiva pós-colonial, uma divisão socioeconômica e política que abarca, por um lado, os países desenvolvidos (Norte Global), e, por outro, os países subdesenvolvidos e em desenvolvimento, além de regiões pobres e grupos minoritários situados no Norte Global (Sul Global). 
cupados em destacar os processos de tradução e recepção de seus trabalhos vinculados à educação, bem como do debate que ele gerou no Brasil. Procura-se evidenciar os percursos e os embates nesse processo, dialogando tanto com sua incorporação na agenda da sociologia em geral ${ }^{3}$ quanto da SE no Brasil.

\section{A sociologia francesa nos trópicos: antessala para a difusão do pensamento bourdiesiano}

Já nos primeiros autores do chamado "Pensamento Social Brasileiro", ainda em finais do século XIX, encontramos uma forte influência do positivismo francês. Todavia, isso não significa que os autores brasileiros transplantassem as ideias francesas de forma mecânica. Como nos indica Villas Bôas (2006), houve uma leitura do positivismo no Brasil que levou à elaboração de uma interpretação da sociedade brasileira com base em uma combinação de diferentes autores e tradições intelectuais.

Essa heterogeneidade também pode ser percebida na elaboração dos primeiros manuais de sociologia escritos no Brasil, publicados entre os anos de 1920 e 1940. De acordo com Meucci (2011), além de Auguste Comte aparecer recorrentemente como "pai da sociologia", autores como Le Play e Durkheim eram centrais nesses manuais, sendo os principais expoentes teóricos nessa produção; todavia, merece atenção o fato de que autores americanos e alemães também eram utilizados recursivamente na elaboração das interpretações sociológicas presentes nesses livros. É ainda nesse período que se difundem no Brasil as cátedras de sociologia, primeiramente nas escolas secundárias, incluindo as Escolas Normais, que eram centros de formação de professores. Nessas escolas, a obra Educação e sociologia, de Durkehim, tornou-se especialmente popular, tendo sido publicada postumamente na França em 1922 e traduzida para o português por Lourenço Filho (1897-1970) em 1929. Enquanto na França a obra teve uma segunda edição apenas em 1966, no Brasil ela foi continuamente reeditada (Nogueira, 2011). Esse livro ainda influenciou decididamente a publicação de Sociologia educacional (1940), de Fernando de Azevedo (1894-1974), e do livro com o mesmo título, Sociologia educacional (1933), de Delgado de Carvalho ${ }^{4}(1884-1980){ }^{5}$

Pode-se perceber com isso que a sociologia francesa ocupa um locus particularmente relevante no âmbito da formação de professores no Brasil. Atenta-se ainda para o fato de que a sociologia fora introduzida no ensino secundário brasileiro visando à modernização dos currículos escolares, e que a transformação dos cursos de formação de professores era considerada essencial nesse processo, uma vez que seria necessário um novo professor para uma nova sociedade (Cury, 1988).

Some-se a isso o fato de que, no período de criação dos primeiros cursos de ciências sociais no Brasil na década de 1930, a influência francesa também foi decisiva, com destaque para a missão francesa que participou da fundação da Universidade de São Paulo. ${ }^{6}$ Roger Bastide (1898-1974), por exemplo, teve um papel central na institucionalização da sociologia brasileira, tendo permanecido no Brasil entre

3 Uma análise que abarca a apropriação do pensamento de Bourdieu por parte das ciências sociais no Brasil, com suas três frentes - sociologia, antropologia e ciência política -, foi recentemente publicada por Campos e Szwako (2020).

4 É importante destacar o fato de que tanto Lourenço Filho quanto Delgado de Carvalho estavam ligados ao movimento da Escola Nova, sendo signatários do Manifesto dos Pioneiros da Educação (Martins, 2003): enquanto o primeiro estava preocupado com uma renovação científica do sistema educativo, o segundo se colocou como tarefa a divulgação da visão escolanovista acerca da sociologia e do caráter prático dessa ciência (Meucci, 2011).

5 Ambos os autores estiveram envolvidos no processo de institucionalização da sociologia no Brasil, uma vez que Carvalho fora o primeiro professor de sociologia do Colégio Pedro II em 1925, e Azevedo, o primeiro catedrático de sociologia na Universidade de São Paulo, em 1933.

6 Esta "missão" iniciou-se em 1934, quando chegaram Émile Coornaert (história), Pierre Deffontaines (geografia), Robert Garric (literatura francesa), Paul-Arbousse Bastide (sociologia), Étienne Borne (filosofia e psicologia) e Michel Berveiller (literatura greco-latina) - somente Berveiller e Arbousse-Bastide renovaria os seus contratos com a universidade no ano seguinte. Em 1935, chegaram ainda Fernand Braudel (história), Pierre Hourcade (literatura francesa), Pierre Monbeig (geografia), Claude Lévi-Strauss (segunda cadeira de sociologia) e Jean Maugüé (filosofia). Monbeig e Maugüé permanecem no país até 1944 e 1947, respectivamente. A partir de 1938, chegou um novo grupo de docentes composto pelos seguintes nomes: Jean Gagé (no lugar de Braudel), Alfred Bonzon (literatura francesa), Paul Hugon (economia) e Roger Bastide (substituto de Lévi-Strauss). 
1938 e 1984 (Queiroz, 1994), e tendo orientado ainda estudantes brasileiros que foram realizar seus estudos pós-graduados na França posteriormente.

Quando ocorreu a criação do atual sistema de pós-graduação existente no Brasil, com a Reforma Universitária em 1968, também percebe-se uma intensa circulação de cientistas sociais brasileiros que foram para o exterior realizar sua formação doutoral, sendo a França um dos principais destinos para tanto (Lima, 2019). Em muitos casos, os pesquisadores que realizaram seus doutorados nesse país foram os principais responsáveis pela divulgação de Pierre Bourdieu no Brasil. Esse fenômeno também se repetiu no campo das ciências da educação, sendo o Brasil um dos países que contou com um dos maiores números de estudantes realizando estudos pós-graduados na França nesse campo do conhecimento (Nogueira, 2011). ${ }^{7}$

Essa passagem panorâmica pela formação das ciências sociais no Brasil visa a demonstrar ao leitor que a recepção de Bourdieu no país está mediada também por uma forma particular pela qual o campo acadêmico das ciências sociais brasileiras se relacionou com as ciências sociais francesas, marcada por uma forte influência dessa tradição europeia nesse país, talvez mais que em outros países latino-americanos. ${ }^{8}$ Sendo assim, a circulação intelectual ocupa um lugar central nesse processo, estabelecendo determinada tradição com relação às discussões acadêmicas e construções teóricas. Obviamente que tal circulação obedece a uma lógica própria e bem estabelecida do centro para as semiperiferias, e destas para as periferias (Sapiro, 2014).

Pensando, como o próprio Bourdieu (Bourdieu et al., 2010), nas condições de possibilidade que foram necessárias para que sua obra passasse a fazer parte da cena acadêmica da SE brasileira, é preciso apontar que o estreitamento entre França e Brasil no processo de autonomização da própria sociologia neste segundo país se apresenta como fator determinante. A posição que a sociologia francesa ocupava mundialmente no início do século XX contribuiu necessariamente para a difusão das obras dos sociólogos francófonos e para a tomada do positivismo ali edificado como perspectiva para as interpretações acerca da sociedade brasileira. Tal difusão - que foi acompanhada pelo papel de destaque de sociólogos franceses que se ocuparam da educação nos primeiros manuais de sociologia brasileiros, com destaque especial para Durkheim, bem como pela missão francesa e pelos trânsitos de pesquisadores brasileiros que foram realizar sua formação na França - começa, na segunda metade do século XX, a contemplar as primeiras obras de Pierre Bourdieu e as apropriações que passaram a ser construídas no Brasil, como veremos a partir de agora.

Essa aproximação intensificou-se no decorrer do século XX com a formação do sistema de pós-graduação no Brasil nas décadas de 1960 e 1970, período no qual houve a criação de um importante sistema de bolsas para que pesquisadores brasileiros pudessem realizar a formação pós-graduada no exterior (Martins, 2018). É emblemático que, entre os bolsistas de produtividade na área de sociologia nível 1A, que realizaram majoritariamente seus estudos doutorais entre as décadas de 1970 e 1980, o país mais recorrente para a realização de estudos no exterior foi a França.

Também no campo da educação a presença francesa se destaca. Nogueira (2011) aponta, com base no levantamento junto à Coordenação de Aperfeiçoamento de Pessoal de Nível Superior (Capes), ao Conselho Nacional de Desenvolvimento Científico e Tecnológico (CNPq) e à Fundação de Amparo à Pesquisa do Estado de São Paulo (Fapesp), que a França foi o principal destino no exte-

7 Esse é um elemento que merece atenção do ponto de vista da institucionalização e do desenvolvimento da sociologia da educação no Brasil, posto que a relação entre as áreas da sociologia e da educação é uma de suas marcas constitutivas e que, até a atualidade, promove câmbios de formação e de atuação profissional entre os professores e pesquisadores que se ocupam da SE no país (Oliveira, \& Silva, 2016) - a circulação entre essas duas fronteiras tem se dado, por exemplo, nos cursos de pós-graduação, nos concursos públicos para as universidades, nas publicações em periódicos de ambas as áreas, bem como no estabelecimento de parcerias de pesquisa.

8 Para compreender de forma mais aprofundada as apropriações e críticas que Pierre Bourdieu recebeu na América Latina, consultar o livro de Moraña (2014). 
rior para a realização de estudos pós-graduados entre 1987 e 1998. No conjunto de orientadores que receberam estudantes brasileiros, destaca-se o nome da socióloga da educação Viviane Isambert-Jamati (1924-2019), considerada uma das fundadoras das ciências da educação naquele país. Isambert-Jamati orientou tanto pesquisadores que realizaram seu doutorado em ciências da educação quanto em ciências sociais, e alguns de seus orientandos tornaram-se referências em seus campos de atuação, tais como, Maria Alice Nogueira (Universidade Federal de Minas Gerais - UFMG), Carlos Benedito Martins (Universidade de Brasília - UnB), Maria Lourdes Bandeira (UnB), Nadir Zago (Universidade Federal de Santa Catarina - UFSC), Lea Pinheiro Paixão (Universidade Federal Fluminense - UFF), José Baia Horta (Universidade Federal do Rio de Janeiro - UFRJ), Ester Buffa (Universidade Federal de São Carlos - UFSCar), Menga Lüdke (Pontifícia Universidade Católica do Rio de Janeiro - PUC-Rio), dentre outros.

Esses elementos ressaltam a centralidade que a circulação internacional entre o Brasil e a França teve no campo acadêmico da sociologia no Brasil, com destaque para a SE, uma vez que muitos dos autores citados tornaram-se lideranças nesse campo, fundando grupos de trabalho nessa seara em sociedades científicas, como a Associação Nacional de Pós-Graduação e Pesquisa em Ciências Sociais (Anpocs), a Associação Nacional de Pesquisa e Pós-Graduação em Educação (Anped), a Sociedade Brasileira de Sociologia (SBS), etc., bem como grupos de pesquisa e observatórios, cadastrados no Diretório do CNPq, que têm como marca um aporte teórico baseado no diálogo entre a sociologia da educação francesa e a sociologia da educação brasileira.

\section{As leituras de Bourdieu no Brasil: uma mirada com base na SE}

Os primeiros textos de Bourdieu passaram a ser traduzidos no Brasil ainda no final da década de 1960, com a publicação do artigo "Campo intelectual e projeto criador" na coletânea Problemas do estruturalismo, por iniciativa do antropólogo Moacir Palmeira, que havia cursado os seminários de Bourdieu na Escola de Altos Estudos em Ciências Sociais nessa mesma década na França. Também vale mencionar a publicação, em 1968, da coletânea Sociologia da juventude, organizada por Sulamita Britto, que publicou em seu volume 4 o artigo "O tempo e o espaço no mundo estudantil", de Pierre Bourdieu e JeanClaude Passeron. Segundo Bortoluci et al. (2015), é interessante perceber que a entrada de Bourdieu no Brasil se deu principalmente por meio da antropologia, e só posteriormente pela sociologia.

Moacir Palmeira narra que esteve na França realizando seus estudos doutorais na década de 1960 quando começou a se aproximar das ideias de Bourdieu e de Althusser, estreitando os laços acadêmicos na década seguinte. Segundo o antropólogo, "ampliamos em meados dos anos 1970 a relação que eu havia estabelecido com os pesquisadores coordenados, no Centre de Sociologie Européenne, por Pierre Bourdieu, quando assistia seus seminários no meu período de doutoramento na França (Lopes, 2013a, p. 446).

Peters e Rocha (2020) ressaltam o papel que o Centre de Sociologie Européenne (CSE) e o Centre de Sociologie de l'Éducation et la Culture (CSEC) tiveram na formação de uma rede de pesquisadores brasileiros e franceses, destacando-se como principal mediadora nesse processo Monique de Saint Martin. Essa socióloga francesa era especialista em sociologia das grandes escolas, o que a levou a uma posição privilegiada na mediação com os especialistas no campo da SE por meio de trocas intelectuais diversas que por vezes não implicavam a existência de uma orientação acadêmica formal. Carlos Benedito Martins, por exemplo, enfatiza o seu papel no processo de aproximação com o grupo de Bourdieu:

E aí a Monique me introduziu no grupo do Bourdieu. Quer dizer, eu era orientando da Viviane Isambert Jamati; mas, na verdade, quem me orientava na minha tese era a Monique, a Monique junto com o Bourdieu. Era um grupo pequeno naquela época. (Oliveira, 2019, p. 18) 
Essas pistas nos ajudam a compreender que os processos de mediação e recepção da obra de Bourdieu no Brasil passam, necessariamente, por um complexo processo de construção de vínculos profissionais e pessoais nem sempre tangíveis institucionalmente. Peters e Rocha (2020) chegam a destacar como isso implicou num primeiro momento um processo de disputas em torno da recepção de Bourdieu no Brasil, cujo polo que conseguiu alcançar uma posição "quase hegemônica" nesse processo foi aquele vinculado à Universidade de São Paulo (USP), e mais especificamente ao grupo de pesquisadores vinculados a Sérgio Miceli. Pinheiro Filho (2009) destaca que as condições editoriais, de ensino e de pesquisa da USP possibilitaram melhores condições de uma recepção durável da obra de Bourdieu - isso implica dizer que as leituras de um autor que acabam consagrando-se em determinado país são, necessariamente, fruto das disputas e das posições das instituições e dos agentes envolvidos no jogo científico, as quais acabam por determinar o seu poder relativo na legitimação de um caminho interpretativo.

Apesar de a difusão de Bourdieu se iniciar no Brasil no campo da antropologia com a introdução de seus textos nos cursos ministrados por Moacir Palmeira no Museu Nacional, é com a publicação de A economia das trocas simbólicas (1974), coletânea de textos de Bourdieu organizada por Sergio Miceli - que estava se preparando naquele momento para realizar seus estudos de doutorado sob a supervisão de Bourdieu na França -, que sua obra passa a se popularizar no Brasil.

Como introdução a essa coletânea, Miceli escreveu o texto "A força do sentido", no qual ele aponta para a singularidade e originalidade do sociólogo francês, que naquele momento ainda não gozava do prestígio que atualmente lhe é conferido. Nessa introdução, Miceli aponta os diálogos que Bourdieu desenvolve com os autores clássicos e contemporâneos, assim como apresenta seus conceitos centrais para o leitor brasileiro. Ortiz (2013) afirma que essa obra organizada por Miceli tinha o objetivo geral de apresentar ao leitor brasileiro um panorama que se pretendia amplo dos interesses e das metodologias do autor. Miceli acabou por construir um guia de leitura para o conjunto de textos que a obra traz, com vistas a "apresentar a novidade produzida no centro de modo a fazer sentido num sistema intelectual periférico" (Bortoluci et al., 2015, p. 228).

Interessante perceber que, nesse trabalho, Miceli e Bourdieu estabeleceram um diálogo ativo, de modo que a rigor não se tratou de "uma simples tradução de textos", já que o processo de seleção dos trabalhos fora discutido conjuntamente entre os dois por meio de uma parceria intelectual. De acordo com o depoimento de Miceli:

A gente tinha esse grupo na PUC, de estudos. E, uma vez... A gente lia Les Temps Modernes, essas coisas. Tinha um número especial sobre os problemas do estruturalismo. O estruturalismo estava na moda, a gente lia tudo de estruturalismo - Levi Strauss, La pensée sauvage, isso tudo era obsessão. E tinha um artigo do Bourdieu chamado O Campo Intelectual e Projeto Criador. Eu li e fiquei fascinado. Eu disse para o pessoal: "Olha gente, vamos fazer um seminário sobre o texto, porque esse cara, realmente, dá uma... Ele tem uma rota para a sociologia da cultura, diferente dessa coisa mais quadradona”. E, aí, nós discutimos o texto e eu comecei a olhar o que tinha dele - de livro que já tinha publicado. Então, eu fui ler: A Reprodução, Les héritiers... Depois que eu li uns dois ou três, eu disse: "Quem sabe fazer uma seleção desse cara que é tão bacana". Aí eu escrevi para ele, e ele me mandou as coisas que eu não conhecia e disse: "Pensa no que você acha que vai funcionar mais no Brasil, e você faz a proposta". Nós temos uma correspondência. Aí eu fiz uma proposta. Ele disse: "Ah, tudo bem. Essa proposta está boa, mas eu acho que você deve incluir isso e tirar isso". Ele fez umas ponderações, e eu fui. Até que fechamos a coisa. Eu distribuí a tradução, fiz alguns dos textos e fiz aquela introdução. Investi, loucamente, naquela tradução. E eu acho que a introdução foi o que, realmente, pegou ele. (Barros, 2012, pp. 11-12)

Miceli conta ainda que foi Bourdieu quem escolheu o título da coletânea e que estava particular- 
mente empolgado com a ideia por ser a primeira grande coletânea de textos dele, uma vez que havia saído apenas uma menor na Alemanha poucos anos antes. Em que pese a relevância que o trabalho de Miceli teve como divulgador da obra de Bourdieu no Brasil, é importante considerar que essa orientação teórica não foi incorporada sem resistências na USP. Como bem destaca Lopes (2013b), a plena legitimação da sociologia de Bourdieu nessa universidade é relativamente recente, ocorrendo depois que tanto Miceli já era renomado nacionalmente, quanto Bourdieu, internacionalmente.

Em ambos os casos, percebemos a relevância que teve para o desenvolvimento desse projeto editorial de tradução de Bourdieu para o português brasileiro a circulação de pesquisadores do Brasil no contex to francês. Portanto, Bourdieu passou a ser traduzido e introduzido no campo intelectual nacional por meio, principalmente, de seus ex-alunos brasileiros que realizaram seus cursos de doutorado na França, e que, no Brasil, passaram a ocupar posições estratégicas em universidades e editoras - traduzindo obras, trabalhando como verdadeiros divulgadores de seus escritos e também influenciando aqueles com os quais estabeleciam parcerias aqui no Brasil, como colegas de trabalho e orientandos.'

Nessa coletânea organizada por Miceli constava a tradução do artigo "Sistemas de ensino e sistemas de pensamento", originalmente publicado na Revue Internationale des Sciences Sociales em 1967. Continha ainda um apêndice intitulado "A excelência e os valores do sistema de ensino francês", originalmente publicado na revista Annales em 1970. A presença desses artigos - publicados após $O$ s herdeiros, porém antes de $A$ reprodução - aponta para o reconhecimento da centralidade da questão educacional na obra de Bourdieu, além de nos oferecer pistas dos caminhos das primeiras apropriações que a SE brasileira realizou no âmbito do pensamento educacional bourdieusiano.

Seria possível inferir, portanto, que, desde o princípio, Bourdieu é introduzido no Brasil como um autor fortemente vinculado ao debate educacional. Essa questão obviamente o liga à análise dos sistemas de ensino, mas também reconhece seu papel como investigador do campo acadêmico e intelectual, o que se tornará mais evidente em obras publicadas posteriormente - e, ainda mais recentemente, nas autorreflexões, ou na sociologia da sociologia, que passou a ser realizada mais sistematicamente pelos pesquisadores sobre a comunidade científica brasileira.

Ademais, como bem destaca Weber (2011), os processos de transformação pelos quais passava o sistema de ensino brasileiro entre as décadas de 1960 e 1970, marcado por uma expansão tardia, impulsionada pelo processo de industrialização e urbanização iniciado no Centro-Sul do país, construíam um terreno fértil para a recepção da sociologia francesa no campo da educação, uma vez que:

Essa produção, que deslocava o debate da instância escolar para a sociedade, propiciou no Brasil a crítica à visão tecnicista de origem americana que, então, presidiam o debate e a política educacional. Tal deslocamento, certamente influenciado pelos acontecimentos de maio de 1968, na França, como assinalam alguns autores, constituía uma tentativa de clarificar o sentido da desigualdade de oportunidades vigente na sociedade ocidental e, sobretudo, revelar que mudanças sociais significativas não poderiam ser promovidas pela instância escolar. (Weber, 2011, p. 165)

Ainda nesse contexto, a primeira obra de Bourdieu a que o público brasileiro teve acesso na íntegra em português foi justamente $A$ reprodução, publicada no Brasil em 1975, apenas cinco anos após sua publicação em francês. Por outro lado, a obra Os herdeiros demorou 50 anos para ser publicada em português. Pode-se levantar como hipóteses sobre o porquê do ávido interesse pela primeira e do parco interesse pela segunda o fato de, em $A$ reprodução, haver a proposta de elaboração de uma teoria geral

9 Estas posições no interior do campo acadêmico podem ser exemplificadas por um relato de experiência feito por Afrânio Mendes Catani (2002), que revela que, na década de 1970, quando começou a trabalhar com Sérgio Miceli, acentuaram-se as suas leituras dos escritos de Pierre Bourdieu - Catani acrescenta um elemento interessante a esse processo de aproximação à obra de Bourdieu nos ciclos acadêmicos paulistas, informando que teve acesso a obras como Los estudiantes y la cultura em castelhano (do original, Les héritiers: les étudiants et la culture), edição adquirida pela biblioteca da Fundação Getulio Vargas em 1971. 
do sistema de ensino, que possibilitaria uma mais fácil incorporação de seus conceitos nas pesquisas a serem desenvolvidas no Brasil (Oliveira, 2018a). Ademais, $A$ reprodução foca na instituição escolar de educação primária e secundária, que estavam em processo de expansão nesse momento sem ter atingido ainda a universalização de acesso.

Antes mesmo da tradução para o português de $A$ reprodução, é importante indicar que foi publicada uma resenha desse livro de autoria de Elba de Sá Barretto, em 1972, na revista Cadernos de Pesquisa. Percebe-se pela resenha como ainda era incipiente a recepção de Bourdieu no Brasil. Segundo esse trabalho: $\mathrm{Na}$ impossibilidade de obter dados mais precisos sobre os autores, resta-nos a indicação de que eles publicaram, sobretudo na década dos 60 , uma série de obras que versam sobre problemas ligados à sociologia e à educação. É também fato conhecido que o professor Bourdieu tem se dedicado notadamente ao estudo das estruturas de poder. (Barretto, 1972, p. 97)

Segue-se então uma sintética apresentação da obra, que possibilitou ao leitor brasileiro uma primeira aproximação a essa que vem a ser uma das principais obras de SE do século XX. Em suas considerações finais sobre o livro, Barretto (1972) realiza a seguinte crítica:

Construindo um esquema de interpretação inteiramente fechado sobre si mesmo, Bourdieu e Passeron deixaram de conferir - a não ser no plano utópico - um lugar lógico para a possibilidade crítica que eles próprios representam através da análise pertinente das relações do sistema de ensino com o sistema de classes. A teoria rigorosamente dedutiva da reprodução social determinada pela reprodução da própria instituição educativa, deixa de considerar o momento em que o sistema, ao lado da sua atribuição reprodutora, engendra também um movimento no sentido de superação desse círculo vicioso. E seria surpreendente se os autores não reconhecessem o seu esforço analítico dentro desta perspectiva.

Nesse sentido, parece-nos que é a falta de uma perspectiva histórica que impede a colocação adequada das possibilidades dialéticas do sistema de ensino, que, se não chega a ser o elemento determinante da transformação de uma dada constelação de poder, pode contribuir de alguma maneira para que essa constelação se altere. (Barretto, 1972, p. 99)

Dez anos depois, também na revista Cadernos de Pesquisa, Durand (1982) aponta que A reprodução foi publicada numa "tradução a seco", sem notas ou comentários que contextualizassem a obra no Brasil, nem ao menos uma apresentação, tendo uma recepção bastante crítica por parte de alguns sociólogos do campo educacional, como Freitag (1977) e Cunha (1979). Para Durand (1982), a partir da publicação desse livro, Bourdieu e Passeron passam a ser percebidos, no campo acadêmico brasileiro, como autores de uma sociologia reacionária, ou ainda de um pessimismo pedagógico (Gomes, 2005). Cunha (1982, p. 57), em resposta à análise de Durand, aponta que "Erram tanto os que julgam a teoria da violência simbólica absolutamente falsa (reacionária, etc.), quanto os que a veneram como absolutamente verdadeira, não admitindo que possa ter limitações, erros e contradições". Todavia, isso não impossibilitou a ampla difusão da obra, ainda que com uma recepção bastante controversa.

Deve-se ter em mente ainda que é em $A$ reprodução que Bourdieu apresenta pela primeira vez o conceito de habitus, posteriormente retrabalhado em Esquisse d'une théorie de la pratique (1972) e ao longo dos anos em dezenas de artigos e livros publicados. Sendo assim, trata-se de uma obra que se mostra fundamental não apenas para a compreensão de sua sociologia da educação, como de seu arsenal teórico como um todo. Além disso, tanto Ortiz (2013) quanto Nogueira (2011) apontam a publicação desse livro no Brasil como um marco no âmbito da pesquisa sobre educação: enquanto o primeiro argumenta que elementos como a contraposição entre as perspectivas de Paulo Freire e Pierre Bourdieu, a aproximação um tanto imprudente entre Althusser e Bourdieu e o contexto da ditadura militar pela qual o país passava devem ser considerados para se pensar no impacto de $A$ reprodução em solo brasileiro; a segunda afirma que a partir dessa obra a influência de Bourdieu jamais declinou no país, sobretudo pela revolução paradigmática que sua teoria da reprodução ocasionou na pesquisa educacional. 
Outros trabalhos de Bourdieu relacionados à educação foram publicados ainda na década de 1970. Na coletânea Educação e hegemonia de classe (1979), organizada por José Carlos Durand e Lia Machado, havia dois artigos de autoria de Bourdieu, "A comparabilidade dos sistemas de ensino" de Bourdieu e Passeron, e "As estratégias de reconversão", de Bourdieu, Luc Boltanski e Monique de Saint--Martin. Como bem destaca Catani (1980), ao analisar essa coletânea percebe-se que ela é composta ainda por textos de outros colaboradores de Bourdieu, e tem como preocupação central trazer ao leitor brasileiro textos que têm como referência a sociedade capitalista contemporânea, e apresentam uma reflexão sobre como a educação colabora na reprodução do consenso necessário para a reprodução de classes. Pode-se inferir que a atualidade do debate para o Brasil residiria, portanto, no fato de essas reflexões serem sobre a sociedade capitalista contemporânea, na qual nós estaríamos inseridos.

Como bem destaca Ortiz (2013), chama a atenção o fato de que, no contexto brasileiro, houve uma leitura que aproximava as ideias de Bourdieu presentes em $A$ reprodução e aquelas presentes em Althusser no livro Os aparelhos ideológicos do Estado. Apesar de podermos perceber diferenças substantivas entre as duas obras, para Ortiz essa aproximação criou certas resistências na recepção da obra de Bourdieu no Brasil, especialmente no campo da educação, que passou a percebê-lo como um simples “reprodutivista”. Ainda segundo o autor:

cabe ressaltar no contexto brasileiro o vínculo que se estabelece entre La reprodution e as propostas de Althusser (na França, Bourdieu não é visto como um althusseriano. Há inúmeros pontos que o afastam dessa corrente de pensamento, desde sua relação com o marxismo à contribuição de outros autores como Durkheim e Weber à sua concepção teórica). Há, primeiro, a tese central do livro. Pode-se argumentar que na perspectiva althusseriana a escola seria apenas um "aparelho ideológico de Estado", enquanto para Bourdieu e Passeron sua eficácia dependeria de como o social inscreve-se no habitus individual. Por isso o conceito de mediação é central para os autores. Permanece, entretanto, uma certa convergência entre essas duas concepções. Mas a aproximação com Althusser manifesta-se também na forma como o livro é escrito. Ele se estrutura a partir de afirmações genéricas - as teses -, comentadas em seguida em seções separadas, os escólios, artifício geralmente utilizado em Filosofia e particularmente por Althusser em diversos de seus trabalhos. O fato é que este vínculo reforçou uma certa resistência em relação aos trabalhos de Bourdieu entre nós. (Ortiz, 2013, pp. 84-85)

Ainda acerca dos pontos de proximidade e distanciamento entre Bourdieu e Althusser, especialmente no campo da educação, Rodrigues (2017, p. 301) realiza o seguinte comentário:

Nesse âmbito, o interessado no "marxismo de/em Bourdieu”, arregala os olhos, e começa a estabelecer nexos de aproximação, posto que o ar de família entre um dos livros produzidos nesta fase A reprodução - e a noção de "aparelhos ideológicos de Estado", de Althusser, seja evidente. Como sói ocorrer, o envelhecimento impõe denegações do passado em que se engendrava um projeto autoral, mas ainda não se era um "autor". Ele não apenas denegaria esse elo, criticando a "sociologia do Aparelho" (Bourdieu, 1989), como também elaboraria análises tão diferentes das apresentadas neste livro, que poderiam ser atribuídas a outra pessoa. Com o avanço das pesquisas empíricas, a sociologia educacional praticada por Bourdieu abandonará as sentenças categóricas d'A reprodução, e se ocupará para as práticas específicas de inculcação e incorporação dos habitus (de classe/escolares), assim como da parte ativa dos dominados na reposição das relações de dominação.

Particularmente compreende-se aqui os argumentos de Ortiz e Rodrigues como não excludentes, uma vez que de fato percebemos $A$ reprodução e Os aparelhos ideológicos do Estado como obras que partem de pressupostos teóricos, e principalmente metodológicos, substancialmente distintos. Todavia, é no desdobramento dos trabalhos posteriores do autor que essas diferenças ficam mais evidentes, em especial no que tange ao tratamento que Bourdieu passa a dar à dimensão cultural, com a defesa progressiva por sua maior autonomia. 
Ainda com relação à recepção dessa obra, é interessante pontuar que, no momento da publicação de $A$ reprodução no Brasil, havia um intenso debate em torno da obra de Paulo Freire que, justamente, buscava destacar a dimensão emancipadora da escola, especialmente em relação às classes populares. ${ }^{10}$ Pode-se inferir, portanto, que a adesão às teorias de Freire no campo educacional também se desdobrou em alguma resistência às ideias de Bourdieu no Brasil num primeiro momento. Catani et al. (2001), ao analisarem a recepção da obra de Bourdieu no campo educacional brasileiro, apontam para o fato de que esse campo esteve marcado, sobretudo nas décadas de 1970 e 1980, por uma orientação que se voltava para a busca de resolução de problemas práticos. Desse modo, a teoria de Bourdieu, num primeiro momento, parecia não confluir com as demandas que se apresentavam no campo educacional.

Ainda no escopo da incorporação de sua teoria de modo mais amplo, podemos dizer que Bourdieu fora percebido mais como um sociólogo da dominação que das resistências num primeiro momento, o que reforçou suas ressalvas no campo educacional. Essa leitura acabou sendo reforçada pelo fato de ter havido uma incorporação do debate educacional em Bourdieu normalmente apartado da teoria sociológica que lhe dá corpo (Hey et al., 2018).

Sem embargo, essa leitura que situa Bourdieu como um autor distanciado das tradições críticas, ou ainda subestima sua capacidade de apontar para caminhos práticos, ignora ao menos dois pontos relevantes, nomeadamente: a) a proposta de uma "pedagogia racional" indicada em Os herdeiros, que permite "ao maior número possivel de individuos aprender no menor tempo possivel, o mais completamente o o mais perfeitamente possivel, o maior número possivel de aptidóes que caracterizam a cultura escolar em um dado momento" (Bourdieu \& Passeron, 2014, p. 101, itálicos dos autores) - pedagogia racional e democratização andariam juntos, e deveriam ter por base uma sociologia das desigualdades culturais; e b) a relação da obra de Bourdieu com o próprio marxismo é bastante complexa, marcada por distintos pontos de aproximação e distanciamento (Bourdieu, 2004) - a obra de Burawoy (2017) é bastante sintomática desses circuitos de interseções possíveis entre o pensamento de Bourdieu e as diferentes tradições marxistas consolidadas ao redor do mundo, pelo que o autor aponta que a maior contribuição do sociólogo francês para tais tradições centra-se na compreensão das classes sociais como formações culturais, e não apenas como formações político-econômico-sociais.

Coloca-se ainda como pano de fundo desse debate o fato de que a Reforma Universitária de 1968 criou as faculdades de educação no Brasil, afastando a sociologia da discussão educacional. Segundo Cunha (1992), esse é um importante ponto de clivagem para compreender o parco interesse dos sociólogos brasileiros pela pesquisa educacional na década de 1970. Ainda que possamos relativizar essa proposição, considerando que a educação perdurou como um tema de investigação em distintos programas de pós-graduação em sociologia no país, que passaram progressivamente por um processo de expansão e incremento de agenda, o fato é que institucionalmente a pesquisa em Sociologia da Educação passou a encontrar cada vez mais espaço para seu desenvolvimento nas faculdades de educação, o que foi acompanhado em muitos casos pela incorporação de sociólogos a seus quadros profissionais.

Na década de 1980 também ganha relevância a publicação de um conjunto de textos de Bourdieu na coletânea Grandes Cientistas Sociais, da editora Ática, coordenada por Florestan Fernandes (19201997). Esse número, publicado em 1983, foi organizado por Renato Ortiz, que havia realizado estudos na França, assim como outros difusores da obra de Bourdieu no Brasil, tendo escrito a introdução "A procura de uma sociologia da prática", que também teve um papel crucial para a apresentação de conceitos fundamentais do autor ao leitor brasileiro. Apesar de não haver nessa coletânea um texto específico sobre educação

10 Desse modo, é compreensível que naquele momento do pensamento educacional brasileiro Freire e Bourdieu fossem tomados como autores diametralmente opostos, sendo o primeiro considerado otimista, e o segundo, pessimista diante do papel da educação e da instituição escolar. Contudo, há que se destacar que as ideias e métodos de Paulo Freire para a escola brasileira estavam pautados exatamente em uma visão crítica de uma escola que ele mesmo denominou de "bancária" e cuja lógica ele assinalou que não contemplava a realidade, os conhecimentos prévios e a visão de mundo dos mais pobres. Nesse sentido, é possível afirmar que o otimismo de Paulo Freire estava centrado no que a escola poderia vir a se tornar, uma vez superadas suas históricas amarras. 
escolar, havia um sobre o campo científico, publicado originalmente na Actes de la Recherche em Sciences Sociales, em 1976, com o título "Le champ scientifique", ampliando o escopo da contribuição de Bourdieu para o debate educacional, considerando a interface com a realidade acadêmica/científica.

Nesse mesmo ano é publicado o emblemático livro Escola e democracia (1999/1983), de Dermeval Saviani, no qual ele analisa as teorias no campo educacional, estabelecendo uma tipologia que abarca três grupos: 1) teorias não críticas; 2) teorias crítico-reprodutivistas; 3) teorias críticas. De acordo com o autor, as teorias crítico-reprodutivistas, por sua vez, se desdobrariam em três subtipos: a) teoria do sistema de ensino enquanto violência simbólica; b) teoria da escola enquanto aparelho ideológico de Estado (AIE); c) teoria da escola dualista. Claramente essa subdivisão se referia aos trabalhos de Bourdieu e Passeron, de Althusser e de Baudelot e Establet, respectivamente, realizando um agrupamento recorrente também fora do Brasil (Snyders, 2005). Na leitura de Saviani (1999), essa teoria afirma simplesmente o papel da escola como reprodutora das desigualdades sociais, sendo uma ilusão pensar na possibilidade de utilizar a escola como superação da marginalidade. Pode-se realizar uma crítica ao trabalho de Saviani na medida em que, como o próprio Bourdieu esclarece em outros trabalhos (Bourdieu, 2011), em A reprodução a escola "pode" colaborar com a reprodução das desigualdades sociais sob determinadas condições - sendo a eficácia da reprodução condicionada ao modo como o social inscreve-se no habitus individual -, portanto, sua teoria não elabora uma sentença fatalista. Sem embargo, o que chama a atenção nessa leitura é que, apesar de compartilhar a tônica mais geral da interpretação vigente de Bourdieu no campo da educação nesse momento, Saviani realiza um esforço de apontar para o caráter não reacionário da obra de Bourdieu e Passeron, uma vez que haveria uma leitura crítica sobre o processo de reprodução social nessa teoria.

Seis anos depois foi publicada a coletânea Escritos de educação, organizada por Afrânio Mendes Catani e Maria Alice Nogueira, dois dos principais divulgadores do trabalho de Bourdieu no campo da educação. Ambos os organizadores seguem a tendência mais ampla apresentada até aqui, de pesquisadores com formação francesa, com a diferença que Maria Alice Nogueira havia recebido sua formação no campo das ciências da educação, e não nos das ciências sociais, o que aponta que a essa altura o processo de incorporação e difusão da teoria de Bourdieu no âmbito da SE já não se restringia ao campo das ciências sociais no seu sentido estrito no Brasil.

Anos mais tarde, em 1999, outro livro bastante difundido no campo educacional brasileiro traz Bourdieu e classifica sua teoria, a exemplo do que fizera Saviani, como teoria crítica; a diferença aqui assenta-se no fato de já haver um uso de Bourdieu no campo do currículo: trata-se da obra Documentos de identidade: uma introdução às teorias do currículo, de Tomaz Tadeu da Silva (2010/1999). Bourdieu e Passeron são brevemente apresentados nesse livro no rol de teorias críticas da educação que influenciaram as teorias críticas do currículo. Tomaz Tadeu da Silva avança no reconhecimento das críticas que essas teorias receberam nas décadas de 1970 e 1980 por seu suposto determinismo econômico e demonstra como a teorização curricular contemporânea nutre-se desse legado.

Balanços mais recentes (Neves, 2002; Martins \& Weber, 2010; Almeida \& Hey, 2018; Barbosa \& Gandin, 2020; Oliveira \& Silva, 2020) apontam para um crescente interesse dos sociólogos brasileiros pela educação, o que ocorre de forma concomitante à expansão do sistema de ensino brasileiro. Pode-se afirmar que a maior parte dos programas de pós-graduação em sociologia tem linhas de pesquisa em educação, ou ao menos linhas de pesquisa mais amplas que abarcam também o debate educacional (Oliveira \& Silva, 2016). Esse movimento ocorre de forma concomitante também à consolidação de linhas de pesquisa em SE em programas de educação, o que aponta para condições objetivas favoráveis para a disseminação do trabalho em SE de Bourdieu em ambos os espaços institucionais.

Esse incremento da pesquisa em SE no Brasil revigora o interesse pela obra de Bourdieu nas pesquisas educacionais, sobretudo a partir da década de 1990, quando o Brasil universaliza o acesso à educação básica. Concomitante a esse movimento, Bourdieu passou a ser o autor mais citado na sociologia brasileira, como indica o balanço feito por Costa (2010), de modo que podemos inferir que a SE também seguiu essa tendência mais geral. Também nas faculdades de educação ele passa a se constituir 
como um autor amplamente referenciado, seguindo uma tendência mais ampla de vinculação entre a SE brasileira e a sociologia francesa, como bem aponta o balanço realizado por Costa e Silva (2003) ao analisarem o GT (grupo de trabalho) "Sociologia da Educação" da Associação Nacional de Pesquisa e Pós-Graduação em Educação (Anped), criado na década de 1990. Todavia, apesar da ampla citação aos trabalhos de Bourdieu no campo da educação no Brasil, devemos considerar que majoritariamente trata-se de citações pontuais, e que apenas uma pequena parte desses trabalhos são desenvolvidos se orientando pelo arsenal teórico do autor (Catani et al., 2001). ${ }^{11}$

Uma hipótese que pode nos ajudar a compreender a difusão de Bourdieu no campo da educação em período mais recente relaciona-se ao fato de ele ter sido lido por um longo período como um "sociólogo da cultura", de forma quase exclusiva, de tal modo que, na medida em que o conceito de cultura passa a ganhar centralidade nas pesquisas educacionais, sua obra também passa a se tornar mais relevante na SE (Medeiros, 2013). Além disso, essa recentralização da questão cultural no campo da pesquisa educacional, em cenário recente, acaba por nos permitir falar de um potencial uso do pensamento bourdieusiano renovado, sobretudo se levarmos em consideração o fato de que, no Brasil, segundo Bortoluci et al., (2015), a sociologia da cultura tem sido a área mais importante para a assimilação da sociologia de Bourdieu.

Sobre a relação da obra de Bourdieu com a sociologia da cultura é necessário abrir um pequeno parêntese. Em primeiro lugar é importante compreender que o próprio paradigma da reprodução no campo educacional em Bourdieu diferencia-se dos debates elaborados por Althusser, assim como por Baudelot e Establet, justamente por deslocar o debate para a dimensão da reprodução cultural (Nogueira, 1990; Oliveira, 2018a), sendo central para o autor a compreensão da cultura escolar e de como ela reproduziria um habitus de classe; em segundo lugar, deve-se ressaltar que recorrentemente as pesquisas em educação são compreendidas dentro de linhas de pesquisa mais gerais nos programas de Sociologia, articulando-se com temas como cultura, ciência e tecnologia, trabalho, etc. (Oliveira \& Silva, 2020).

Essa aproximação com a obra de Bourdieu possibilitou também uma revisita mais complexa de seus conceitos fundamentais. Almeida (2007), por exemplo, problematiza se o conceito de "capital cultural" é útil para a realidade brasileira. Ela reconhece que o sistema escolar brasileiro continua classificando os estudantes com base em sua maior ou menor aproximação da cultura erudita; porém, relativiza o peso desse capital cultural considerando as profundas desigualdades econômicas existentes, que fazem com que os estudantes brasileiros acessem instituições escolares substancialmente distintas.

Nogueira e Nogueira (2002) também apontam que uma das principais críticas de que o trabalho de Bourdieu tem sido alvo remete à diversidade interna dos sistemas de ensino, reconhecendo como um limite de sua teoria a não percepção dessa diversidade com relação às escolas e aos professores. No âmbito empírico, pesquisas como as de Barbosa (2009) apontam para como as escolas e os professores conseguem impactar nas trajetórias sociais e escolares de alunos pertencentes a classes sociais mais pobres.

Nesse ponto pode-se apontar para duas direções nas leituras realizadas da obra de Bourdieu no campo da SE: a) por um lado, as substanciais diferenças entre a sociedade francesa e seu sistema de ensino e a sociedade brasileira tendem a demandar um redimensionamento do papel da escola nos processos de reprodução das práticas, e das desigualdades em particular; b) o reconhecimento de que a sociedade brasileira é uma sociedade estratificada em termos de classes sociais que não superou a questão das desigualdades sociais possibilitaria uma aproximação e um revisitar dos escritos de Bourdieu.

Por fim, é importante destacar que a incorporação ao debate das chamadas "teorias do Sul"12 na SE do Brasil (Oliveira, 2018b) também têm levado a uma revisão crítica do trabalho de Bourdieu. Como nos

11 Um novo horizonte de estudo para aprofundar a compreensão do peso e da influência de Bourdieu no campo da sociologia da educação brasileira poderia assentar-se em uma análise dos trabalhos na pós-graduação que não apenas citam o autor (como já temos na literatura especializada), mas que se valem necessariamente de um aporte teórico bourdieusiano - essa mirada pode fornecer um avanço mais acurado da apropriação de seu pensamento nesse campo.

12 Por teorias do Sul compreendemos o conjunto de teorias produzidas de uma perspectiva do Sul Global, considerando-se a geopolítica do conhecimento existente. 
afirma Connell (2007), um dos limites que apontamos na teoria de Bourdieu para pensar o Sul Global encontra-se, justamente, na ausência da experiência colonial no substrato social que lastreia seu aparato teórico. Considerando-se a realidade escolar brasileira, na qual as desigualdades raciais são centrais para a compreensão das desigualdades sociais, por exemplo, o conceito de habitus, compreendido como um habitus de classe, perderia força. Não se trata com isso de recusar a capacidade heurística da obra de Bourdieu, mas de situá-la criticamente com base no reconhecimento dos limites que não só sua teoria, mas também outras produzidas no Norte Global têm para analisar questões idiossincráticas que se referem a distintas experiências sociais.

Apesar das diferenças substantivas entre as realidades educacionais no Brasil e na França, como já indicado, autores como Catani $(2002)$ e Valle $(2007,2014)$ continuam a perceber a atualidade de Bourdieu e sua pertinência para pensar a realidade escolar brasileira. Compreende-se que há o compartilhamento de alguns dilemas educacionais e sociais entre os dois países, além de perceber que Bourdieu lança mão de ferramentas teóricas e analíticas que poderiam ser úteis para pensarmos a realidade brasileira.

Ressalta-se, por fim, que suas outras obras voltadas mais especificamente para a realidade educacional só passaram a ser lidas em período mais recente no Brasil: Os herdeiros, como já indicado, só foi publicada no Brasil em 2014; Homo academicus, obra de 1984, foi traduzida para o português em 2011; A nobreza de Estado, publicação de 1989, ainda não tem tradução em português; e, mais recentemente, foi publicada a coletânea de textos intitulada Pierre Bourdieu: uma sociologia ambiciosa da educação (2019), organizada por Ione Ribeiro Valle ${ }^{13}$ e Charles Soulié. Isso demonstra que ainda há mais do que se apropriar de Bourdieu, e mais espaço para uma crítica construtiva sobre a capacidade de sua obra elucidar elementos substantivos da realidade educacional no Sul Global. Nesse sentido, segue-se à geração de divulgadores do pensamento bourdieusiano no Brasil as supracitadas novas gerações, que, tendo figurado como orientandos da primeira geração, continuam a trabalhar com um escopo teórico e metodológico ligado ao legado de Bourdieu na interseção entre a sociologia e a educação.

\section{Considerações finais}

Neste breve artigo buscou-se observar, sem exaurir o debate, as formas como Bourdieu foi incorporado no debate brasileiro, especificamente no campo da SE, que foi um dos mais centrais ao longo de sua trajetória acadêmica.

Evidenciou-se que as condições de possibilidade da robustez na apropriação do pensamento bourdieusiano pelos agentes da SE no Brasil nos falam (e devem ser compreendidas a partir) dos movimentos significativos anteriores ao retorno de pesquisadores brasileiros - que ao se dirigirem à França para continuar sua formação estudaram com Bourdieu - bem como anteriores às próprias traduções de seus artigos e livros para a língua portuguesa. Queremos salientar com isso o papel de destaque da sociologia francesa nos processos de autonomização da sociologia brasileira, da missão francesa na Universidade de São Paulo e dos consequentes primeiros trânsitos e parcerias entre sociólogos desses dois países. Esse cenário constituiu condição capital para o interesse e disseminação das ideias de Bourdieu no Brasil.

A difusão realizada no Brasil, por meio de pesquisadores que realizaram a formação doutoral na França, tanto nas ciências sociais quanto nas ciências da educação, foi o principal mecanismo impulsionador desse processo, e, no caso da SE, passou a ter maior ressonância a partir da ampliação das linhas de pesquisa em SE tanto nos programas de pós-graduação em sociologia quanto em educação, uma vez que a orientação de trabalhos nesse nível acabou por também contribuir com os movimentos de disseminação do pensamento de Bourdieu no Brasil, pois os nossos doutores recém-chegados da França passaram a incorporar esse autor em suas disciplinas e nos trabalhos de seus orientandos.

13 A professora Ione Ribeiro Valle, assim como outros organizadores citados neste artigo, realizou seus estudos doutorais na França, no campo das ciências da educação. A pesquisadora foi também responsável pela tradução de Homo academicus e Os herdeiros no Brasil. 
Buscou-se demonstrar ainda que, apesar das resistências iniciais que se desenharam em relação à recepção do trabalho de Bourdieu - o que em parte se deveu a uma leitura de sua obra como incapaz de responder às demandas práticas impostas pelo campo educacional, contrastando com outras teorias que estavam mais em evidência naquele momento -, seu trabalho passou a ser incorporado paulatinamente na agenda de pesquisa da SE no Brasil. Ao longo das últimas décadas, as controvérsias nesse processo de recepção foram se transformando, em função do inegável alcance que suas obras ganharam, em reflexões em torno das marcas e da qualidade da apropriação que vem sendo realizada (Catani et al., 2001), bem como pelo diálogo cada vez mais rico e interdisciplinar, para além dos limites da educação e a correlacionando com áreas como a cultura ou a política, que tem sido promovido nos renovados usos do pensamento bourdieusiano no país (Medeiros, 2013).

Apesar das críticas que vem sofrendo em período mais recente, que se assentam tanto nos limites teóricos que sua teoria apresentaria quanto com relação à realidade empírica, pensando-se desde uma crítica das teorias do Sul, o interesse por sua obra perdura entre pesquisadores brasileiros, que reafirmam sua atualidade e a capacidade de lançar ferramentas relevantes para a compreensão de nossa realidade educacional.

\section{Referências}

Almeida, A. M. F. (2007). A noção de capital cultural é útil para se pensar o Brasil? In N. Zago \& L. Paixão (Org.), Sociologia da educação brasileira: Pesquisa e realidade brasileira (pp. 44-59). Vozes.

Almeida, A. M. F., \& Hey, A. P. (2018). Sociologia da educação: Olhares sobre um campo em ascensão. In S. Miceli \& C. B. Martins (Org.), Sociologia brasileira hoje (pp. 253-310). Ateliê Editorial.

Barbosa, M. L. (2009). Desigualdade e desempenho: Uma introdução à sociologia da escola brasileira. Argvmentvm.

Barbosa, M. L., \& Gandin, L. A. (2020, fev.). Sociologia da educação brasileira: Diversidade e qualidade. Revista Brasileira de Informaçôes Bibliográficas em Ciências Sociais - BIB, 91, 1-38.

Barretto, E. S. de S. (1972, out.). La réproduction: Élements pour une théorie du sistème d'enseignement. Cadernos de Pesquisa, 4, 97-99.

Barros, S. M. P. de. (2012). Depoimento com Sérgio Miceli Pessôa de Barros. CPDOC/Fundação Getulio Vargas (FGV), $2 \mathrm{~h} 5 \mathrm{~min}$.

Bortoluci, J. H., Jackson, L. C., \& Pinheiro Filho, F. A. (2015). Contemporâneo clássico: A recepção de Pierre Bourdieu no Brasil. Lua Nova, 94, 217-254.

Bourdieu, P. (1974). A economia das trocas simbólicas. Perspectiva.

Bourdieu, P. (1989). Escritos de educação. Vozes.

Bourdieu, P. (2004). Coisas ditas. Brasiliense.

Bourdieu, P. (2011). Capital cultural, escuela y espacio social. Siglo XXI.

Bourdieu, P., Chamboredon, J.-C., \& Passeron, J.-C. (2010). Oficio de sociólogo: Metodologia da pesquisa na sociologia. Vozes.

Bourdieu, P., \& Passeron, J.-C. (1968). O tempo e o espaço no mundo estudantil. In S. de Brito (Org.), Sociologia da juventude (pp. 61-86, v. 4.) Zahar.

Bourdieu, P., \& Passeron, J.-C. (2008). A reprodução: Elementos para uma teoria do sistema de ensino. Vozes.

Bourdieu, P., \& Passeron, J.-C. (2014). Os herdeiros: Os estudantes e a cultura. EdUFSC.

Burawoy, M. (2017). O marxismo encontra Bourdieu. Editora da Unicamp.

Campos, L. A., \& Szwako, J. (2020, fevereiro). Biblioteca bourdieusiana ou como as ciências sociais brasileiras vêm se apropriando de Pierre Bourdieu (1999-2018). Revista de Informação Bibliográficas em Ciências Sociais - BIB, 91, 1-25.

Catani, A. M. (1980, abr./jun.). Educação e hegemonia de classes: As funções ideológicas da escola. Revista de Administração de Empresas, 20(2), 70-81. 
Catani, A. M. (2002, abr.). A sociologia de Pierre Bourdieu (ou como um autor se torna indispensável ao nosso regime de leituras). Educação \& Sociedade, 23(78), 57-75.

Catani, A. M., Catani, D. B., \& Pereira, G. R. M. (2001, maio/ago.). As apropriações da obra de Pierre Bourdieu no campo educacional brasileiro, através de periódicos da área. Revista Brasileira de Educação, 17, 63-85.

Connell, R. (2007). Southern theory: The global dynamics of knowledge in social science. Polity Press.

Costa, M. da, \& Silva, G. M. D. (2003, jan./abr.). Amor e desprezo: O velho caso entre sociologia e educação no âmbito do GT-14. Revista Brasileira de Educação, 22, 101-120.

Costa, S. (2010). Teoria por adição. Sociologia da educação: Democratização e cidadania. In C. B. Martins, \& H. H. T. de S. Martins (Orgs.), Horizontes das ciências sociais: Sociologia (pp. 20-36). Anpocs.

Cunha, L. A. (1979, set.). Notas para uma leitura da teoria da violência simbólica. Educação \& Sociedade, I(4), 79-110.

Cunha, L. A. (1982). A violência simbólica da teoria. Cadernos de Pesquisa, 43, 55-57.

Cunha, L. A. (1992). A educação na sociologia: Um objeto rejeitado? Cadernos Cedes, 27, 9-22.

Cury, C. R. J. (1988). Ideologia e educação brasileira: Católicos e liberais. Cortez.

Durand, J. C. (1982, nov.). Torcidas de nariz a Bourdieu e Passeron. Cadernos de Pesquisa, 43, 52-54.

Durand, J. C., \& Machado, L. (Org.). (1979). Educação e hegemonia de classe. Zahar.

Freitag, B. (1977). Escola, Estado e sociedade. Edart.

Gomes, C. A. (2005). A educação em novas perspectivas sociológicas. EPU.

Hey, A. P., Catani, A. G., \& Medeiros, C. C. C. (2018, maio/ago;). A sociologia da educação de Bourdieu na revista Actes de la Recherche en Sciences Sociales. Tempo Social, 30(2), 171-195.

Lima, J. C. (2019, abr.). A reconfiguração da sociologia no Brasil: Expansão institucional e mobilidade docente. Interseçōes, 21(1), 7-48.

Lopes, J. S. L. (2013a, jan./jun.) Entrevista com Moacir Palmeira. Horizontes Antropológicos, 19(39), 435-357.

Lopes, J. S. L. (2013b, jun.). Touraine e Bourdieu nas ciências sociais brasileiras: Duas recepções diferenciadas. Sociologia \& Antropologia, 3(5), 43-79.

Martins, C. B. (2003, out.). Encontros e desencontros da sociologia e educação no Brasil. Revista Brasileira de Ciências Sociais, 18(53), 161-169.

Martins, C. B. (2018). As origens pós-graduação nacional (1960-1980). Revista Brasileira de Sociologia, 6(13), 9-26.

Martins, C. B., \& Weber, S. (2010). Sociologia da educação: Democratização e cidadania. In C. B. Martins \& H. H. T. de S. Martins (Coords.), Horizontes das ciências sociais: Sociologia (pp. 131-201). Anpocs.

Masson, P. (2001). La fabrication des héritiers. Revue Française de Sociologie, 42(3), 477-507.

Medeiros, C. C. C. de. (2013, jan./mar.). Pierre Bourdieu, dez anos depois. Educar em Revista, 47, 315-328,

Meucci, S. (2011). Institucionalização da sociologia no Brasil: Primeiros manuais e cursos.: Hucitec; Fapesp.

Moraña, M. (2014). Bourdieu en la periferia: Capital simbólico y campo cultural en América Latina. Cuarto Propio.

Neves, C. E. B. (2002). Estudos sociológicos sobre educação no Brasil. In S. Miceli (Org.), O que ler na ciência social brasileira 1970-2002 (pp. 351-437). Capes.

Nogueira, M. A. (1990, abr./jun.). A sociologia da educação do final dos anos 60/ início dos anos 70: O nascimento do paradigma da reprodução. Em Aberto, 9(46), 49-58.

Nogueira, M. A. (2011, jan./jun.). Contribuições francesas para o pensamento educacional e a formação de pesquisadores brasileiros. Cadernos de Estudos Sociais, 26(1), 63-69.

Nogueira, C. M. M., \& Nogueira, M. A. (2002, abr.). A sociologia da educação de Pierre Bourdieu: Limites e contribuições. Educação \& Sociedade, 23(78), 15-36.

Nogueira, C. M. M., \& Nogueira, M. A. (2015, jan./mar.). Os herdeiros: Fundamentos para uma sociologia do ensino superior. Educação \& Sociedade, 36(130), 47-62.

Oliveira, A. (2018a, jan./jul.). A atualidade de “Os herdeiros”. Revista Pós Ciências Sociais, 15(29), 303-308.

Oliveira, A. (2018b). Repensando a sociologia da educação no Brasil: Ações afirmativas e teorias do sul. RASE: Revista de Sociología de la Educación, 11(1), 59-69. 
Oliveira, A. (2019). A sociologia brasileira e seus desafios: Entrevista com Carlos Benedito Martins. Politica \& Sociedade, 18(41), 13-26.

Oliveira, A., \& Silva, C. F. da. (2016, jun.). A sociologia, os sociólogos e a educação no Brasil. Revista Brasileira de Ciências Sociais, 31(91), 1-15.

Oliveira, A., \& Silva, C. F. da. (2020). The sociology of education in Brazil today. RASE: Revista de Sociología de la Educación, 13(1), 39-54.

Ortiz, R. (2013, jun.). Nota sobre a recepção de Pierre Bourdieu no Brasil. Revista Sociologia \& Antropologia, 3(5), 81-90.

Peters, G., \& Rocha, M. E. da M. (2020, fev.). Facetas de um Bourdieu tupiniquim: Momentos de sua recepção no Brasil. Revista de Informação Bibliográficas em Ciências Sociais - BIB, 91, 1-30.

Pinheiro Filho, F. A. (2009). The renovation: Aspects of Pierre Bourdieu's reception in Brazil. Sociologica, 1, 1-18.

Queiroz, M. I. P. (1994, set./dez.). Roger Bastide, professor da Universidade de São Paulo. Estudos Avançados, $8(22), 215-220$.

Rodrigues, L. S. (2017). O "Pierre Bourdieu" de marxistas e antimarxistas. Arquivos do CMD, 6(1), 290-305.

Sapiro, G. (2014). Sciences humaines en traduction: Le livre français aux Etats-Unis, au Royaume-Uni et en Argentine. Institut Français.

Saviani, D. (1999). Escola e democracia. Autores Associados.

Silva, T. T. da. (2010). Documentos de identidade: Uma introdução às teorias de currículo. Autêntica.

Snyders, G. (2005). Escola, classe e luta de classes. Centauro.

Valle, I. R. (2007, jan./abr.). A obra do sociólogo Pierre Bourdieu: uma irradiação incontestável. Educação e Pesquisa, 33(1), 117-134.

Valle, I. R. (2014, jul./dez.). Os herdeiros: Uma das principais “teses" da sociologia francesa da educação. Revista Linhas, 15(29), 232-250.

Valle, I. R. \& Soulié, C. (Orgs.). (2019). Pierre Bourdieu: Uma sociologia ambiciosa da educação. EdUFSC.

Villas Bôas, G. (2006). Mudança provocada: Passado e futuro no pensamento sociológico brasileiro. Editora FGV.

Weber, S. (2011, jan./jun.). Alguns aspectos das contribuições francesas para o debate e o sistema educacional brasileiro. Cadernos de Estudos Sociais, 26(1), 161-168.

\section{Nota sobre autoria}

Artigo concebido por Amurabi Oliveira e escrito por ambos os autores.

\section{Disponibilidade de dados}

Os dados subjacentes ao texto da pesquisa estão informados no artigo.

\section{Como citar este artigo}

Oliveira, A., \& Silva, C. F. da. (2021). A recepção de Pierre Bourdieu na sociologia da educação brasileira. Cadernos de Pesquisa, 51, Artigo e07292. https://doi.org/10.1590/198053147292 